\title{
Anthocyanins inhibit trastuzumab-resistant breast cancer in vitro and in vivo
}

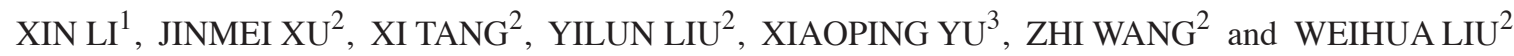 \\ ${ }^{1}$ Administrative Office, Chengdu Medical College; ${ }^{2}$ Department of Scientific Research, \\ First Affiliated Hospital of Chengdu Medical College; ${ }^{3}$ Department of Public Health, \\ Chengdu Medical College, Chengdu, Sichuan 610500, P.R. China
}

Received February 10, 2015; Accepted November 30, 2015

DOI: $10.3892 / \mathrm{mmr} .2016 .4990$

\begin{abstract}
Trastuzumab (Herceptin $\left.{ }^{\circledR}\right)$ is a recombinant humanized monoclonal antibody that is targeted against the human epidermal growth factor receptor 2 (HER2) tyrosine kinase receptor. Trastuzumab has been successfully used to treat patients with HER2-positive breast cancer, which accounts for $\sim 25 \%$ of invasive breast cancer. However, the majority of patients who initially respond to trastuzumab demonstrate disease progression within 1 year of treatment. Therefore, identifying alternative drugs that overcome trastuzumab resistance and target HER2 may increase the magnitude and duration of response. Through a high-throughput screening approach, we previously identified numerous anthocyanins that exert activity in HER2-positive human breast cancer cell lines. The present study aimed to evaluate the anti-tumor properties of anthocyanins against parental HER2-positive cells and derivative trastuzumab-resistant cells in vitro and in vivo. Cell proliferation, western blotting, Annexin V staining, migration and invasion assays were used to determine the effects of anthocyanins in vitro. Cyanidin-3-glucoside and peonidin-3-glucoside were able to inhibit phosphorylation of HER2, induce apoptosis, suppress migration and invasion, and inhibit tumor cell growth. Coupled with the fact that anthocyanins have been used for decades as supplements for the treatment of various types of cancer in Asia, the present study may have established a framework for the development and testing of anthocyanins as a novel treatment paradigm used to overcome classical trastuzumab-resistance and to improve the outcome of this disease.
\end{abstract}

Correspondence to: Dr Weihua Liu, Department of Scientific Research, First Affiliated Hospital of Chengdu Medical College, 287 Baoguang Road, Chengdu, Sichuan 610500, P.R. China E-mail: xinlijournal@live.com

Key words: anthocyanins, cyanidin-3-glucoside, drug-resistant, peonidin-3-glucoside

\section{Introduction}

In the United States, breast cancer is the second most common cause of cancer-associated mortality in women (1). An estimated 60,290 new cases of breast carcinoma in situ were expected to be diagnosed among women in the US during 2015, according to the American Cancer Society (1). Breast cancer accounts for $7-10 \%$ of all malignant tumors, with a $3-4 \%$ increase in the number of new cases occurring each year in China (2).

Overexpression of the human epidermal growth factor receptor 2 (HER2) tyrosine kinase receptor gene has been identified as a negative prognostic factor for node-positive early breast cancer; therefore, understanding the biology of HER2 has revolutionized the classification, prognosis, and treatment of breast cancer $(3,4)$. HER2 is known to be overexpressed in $15-20 \%$ of breast cancer and has an important role in regulating cell survival, proliferation, angiogenesis, invasion and metastasis (5). At present, targeted anticancer drugs, such as the monoclonal antibody trastuzumab (Herceptin ${ }^{\circledR}$ ) have been proven to be effective in clinical settings (6). However, primary resistance to trastuzumab remains a prevalent challenge for the treatment of patients with HER2-positive breast cancer (3). Traditional Chinese herbs and medicines have been reported to be clinically effective in the treatment of cancer; however, the underlying mechanisms of action remain largely unknown. We previously reported a high-throughput in vitro screen of a 10,000 natural product library against six representative breast cancer cell lines, and assessed the cytotoxicity of each drug (7). Out of the eight natural compounds that selectively inhibit the proliferation of HER2-positive cells, two anthocyanins: Peonidin-3-glucoside (P3G) and cyanidin-3-glucoside (C3G) were studied in vitro and in vivo (7). Subsequently, we investigated the combined antitumor effects of $\mathrm{P} 3 \mathrm{G}$ or $\mathrm{C} 3 \mathrm{G}$ with trastuzumab on representative HER2-positive breast cancer cell lines and on a tumor xenograft model, and demonstrated that the anthocyanins were able to significantly enhance trastuzumab-induced growth inhibition (8).

The present study aimed to characterize the mechanisms underlying the activity of $\mathrm{P} 3 \mathrm{G}$ and $\mathrm{C} 3 \mathrm{G}$ against HER2-positive trastuzumab-resistant human breast cancer cell lines. Elucidation of the mechanisms of action of $\mathrm{P} 3 \mathrm{G}$ and $\mathrm{C} 3 \mathrm{G}$ may enhance the understanding of breast cancer and result in identification of novel treatment strategies. 


\section{Materials and methods}

Reagents. Unless otherwise stated all chemicals and reagents (analytical grade) were purchased from Sigma-Aldrich China, Inc. (Shanghai, China). Trastuzumab was a gift from the Pharmacology Department of Chengdu Medical College (Chengdu, China), and was originally purchased from Roche Diagnostics (Shanghai, China) with $>98 \%$ purity. P3G and C3G were purchased from Pharmanic (Chengdu, China) with $>98 \%$ purity.

Cell lines and culture conditions. Parental cells were obtained from the American Type Culture Collection (Manassas, VA, USA). MDA-MB-453 cells were maintained in Dulbecco's modified Eagle's medium (DMEM) supplemented with $2 \mathrm{mmol} / \mathrm{l} \mathrm{L}$-glutamine. BT474 cells were maintained in DMEM:Ham's F12 medium (1:1 mixture) supplemented with $2 \mathrm{mmol} / \mathrm{l} \mathrm{L}$-glutamine and $5 \mu \mathrm{g} / \mathrm{ml}$ insulin. Resistant lines (MDA-MB-453R and BT474R) were developed by continuously exposing cells to trastuzumab $(8 \mu \mathrm{g} / \mathrm{ml})$ until the cells regained morphology similar to that of the parental line ( $\sim 3$ months) $(9,10)$. Subsequently, the cells were maintained in $8 \mu \mathrm{g} / \mathrm{ml}$ trastuzumab. All media were supplemented with $10 \%$ fetal bovine serum (FBS) and 1\% penicillin/streptomycin. All cells were maintained in an atmosphere containing $5 \% \mathrm{CO}_{2}$ at $37^{\circ} \mathrm{C}$. Trastuzumab was removed from the media for subsequent experiments.

Cell proliferation assay. Cell proliferation assays were performed as described previously (7). Briefly, MDA-MB-453, MDA-MB-453R, BT474 and BT474R cells were plated at a density of $1 \times 10^{3}$ cells/well in a total volume of $90 \mu 1 /$ well (96-well plates). Cells were allowed to attach to the bottom of the plates overnight, and were then treated with or without $10 \mu \mathrm{l} \mathrm{C} 3 \mathrm{G}$ or P3G (concentration range $0.003-50 \mu \mathrm{M}$ in a $100 \mu \mathrm{l}$ total volume, 4-fold dilution) for $48 \mathrm{~h}$ at $37^{\circ} \mathrm{C}$ in an atmosphere containing $5 \% \mathrm{CO}_{2}$. Aliquots of Alamar-Blue reagents $(20 \mu \mathrm{l})$ were added directly to each well, the plates were incubated at $37^{\circ} \mathrm{C}$ for an additional $3 \mathrm{~h}$, and the fluorescent signal was measured at an excitation wavelength of $530 \mathrm{~nm}$ and an emission wavelength of $590 \mathrm{~nm}$ using a ZS-2 plate reader (Beijing Hongrunda Technology Development Co., Ltd., Beijing, China). Data were normalized as percentage viability relative to the vehicle control (dimethyl sulfoxide), defined as $100 \%$ survival.

Drug treatment for western blotting. MDA-MB-453, MDA-MB-453R, BT474 and BT474R cells were grown to $70-80 \%$ confluence, harvested, and aliquoted into $60 \mathrm{~mm}$ dishes at a density of $1 \times 10^{6}$ cells/dish. After an overnight incubation, media were removed and replaced with fresh media supplemented with or without $5 \mu \mathrm{l} / \mathrm{ml} \mathrm{C3G}$ or P3G. The dishes were incubated for an additional $24 \mathrm{~h}$ prior to harvesting.

Western blot analysis. Western blotting was performed as previously described (7). Briefly, the cells were washed with ice-cold phosphate-buffered saline (PBS) and were scraped into radioimmunoprecipitation assay buffer supplemented with protease inhibitor and phosphatase inhibitor (Roche Diagnostics). The homogenates were centrifuged at the maximum force for $5 \mathrm{~min}$ at $4^{\circ} \mathrm{C}$. The supernatants were then transferred to fresh tubes, and protein concentrations were determined using the Bio-Rad Protein Assay [Bio-Rad Laboratories (Shanghai) Ltd., Shanghai, China], according to the manufacturer's protocol. Total protein samples $(25 \mu \mathrm{g})$ were subjected to electrophoresis [10\% Tris-HCL, $1.0 \mathrm{~mm}$ gel; Bio-Rad Laboratories (Shanghai) Ltd.] and were transferred to polyvinylidene fluoride membranes (Thermo Fisher Scientific, Shanghai, China). The membranes were then blocked in Tris-buffered saline containing $0.05 \%$ Tween 20 (TBST) and $5 \%$ nonfat milk or $5 \%$ bovine serum albumin (BSA) for $1 \mathrm{~h}$ at room temperature. Primary antibodies were diluted to 1:1,000 using TBST/5\% nonfat milk or TBST/5\% BSA, and the membranes were incubated with them for $2 \mathrm{~h}$ at room temperature or overnight at $4^{\circ} \mathrm{C}$. Following three washes with TBST, the secondary antibodies were diluted to $1: 10,000$ using SuperBlock (PBS) blocking buffer (Thermo Fisher Scientific), and the membranes were incubated with them for $1 \mathrm{~h}$ at room temperature. Protein levels were detected using the Enhanced Chemiluminescence (ECL) Plus Western Blotting Detection system (GE Healthcare, Shanghai, China). Following a $5 \mathrm{~min}$ incubation with ECL Plus reagents, the membranes were washed once with TBST, prior to exposure to films. The image was analyzed using ImageJ 1.49 software (National Institutes of Health, Bethesda, MD, USA). The following antibodies purchased from Rui Biological Ltd. (Shanghai, China) were used: Anti-phosphorylated (p)-HER2 (Tyr1248; cat. no. AB-2387), anti-HER2 (cat. no. AB-5569), anti-p-AKT (Thr308 or Ser473; cat. no. AB-2864, AB-2865), anti-AKT (cat. no. AB-2863), anti-p-p42/44 mitogen-activated protein kinase (MAPK) (cat. no. AB-6534), anti-p42/44MAPK (cat. no. AB-6535), anti- $\beta$-actin (cat. no. AB-0230), horseradish peroxidase (HRP)-conjugated goat anti-rabbit immunoglobulin $\mathrm{G}$ (IgG) (cat. no. AB-0025), and (HRP)-conjugated goat anti-mouse IgG (cat. no. AB-0032).

Annexin V-fluorescein isothiocyanate (FITC) assay. An Annexin V-FITC assay was used to detect early apoptotic effects, as previously described (7). Briefly, the cells were treated with or without reagents for $24 \mathrm{~h}$ at $37^{\circ} \mathrm{C}$. The cells were then stained with Annexin-V-FITC antibody (cat. no. A13199;Thermo Fisher Scientific, Inc., Waltham, MA, USA; supplied by the Chengdu Medical College Flow-Cytometry Core Facility) for $15 \mathrm{~min}$ in the dark on ice. Propidium iodide (PI; $1 \mathrm{~g} / \mathrm{ml}$ ) was added immediately prior to analysis. The cells were analyzed using CyFlow ${ }^{\circledR}$ ML (Sysmex Partec GmbH, Görlitz, Germany). Bivariant analysis was used to define the population of cells, where FITC (-) and PI (-) cells were designated as viable cells, FITC (+) and PI (-) cells were designated as apoptotic cells, and FITC (+) and PI (+) cells were designated as late apoptotic or necrotic cells.

Caspase 3/7 activity assay. The apoptotic effects of drug treatment were assessed using a caspase 3/7 activity assay as described previously (7). Following a $48 \mathrm{~h}$ drug treatment, aliquots of Alamar-Blue reagent (20 $\mu \mathrm{l} /$ well) were added directly to each well, the plates were incubated at $37^{\circ} \mathrm{C}$ for $3 \mathrm{~h}$ and the fluorescent signal was recorded at an excitation wavelength of $530 \mathrm{~nm}$, and an emission wavelength of $590 \mathrm{~nm}$, using a ZS-2 plate reader (Beijing Hongrunda Technology Development Co., Ltd.). Subsequently, equal volumes 
(120 $\mu \mathrm{l} /$ well) of caspase 3/7 activity assay reagent (Shanghai Promega Biological Products, Ltd., Shanghai, China) were added to each well and the luminescence signal was measured. Caspase 3/7 activities were normalized as fold-changes of luminescence relative to fluorescence.

Migration and invasion assays. Migration and invasion assays were conducted using a Transwell $(8 \mu \mathrm{m}$; Merck Millipore, Beijing, China) double chamber co-culture system. Briefly, $1 \times 10^{4}$ cells were seeded into the upper chamber of 24-well plates, which were coated with Matrigel (migration assay) or $1 \mathrm{mg} / \mathrm{ml}$ type I collagen solution (invasion assay). The lower chamber was filled with media supplemented with $10 \%$ FBS. The cells were cultured with medium, or medium supplemented with C3G (1 mg/ml) or P3G $(1 \mathrm{mg} / \mathrm{ml})$, for $48 \mathrm{~h}$. The migrated or invaded cells were fixed and stained with crystal violet. Five random fields were selected for each experiment, and were observed under a microscope (SZX16; Olympus Corporation, Tokyo, Japan). Experiments were performed in triplicate.

Mice xenograft model. In vivo experiment protocols were reviewed and approved by the Chengdu Medical College Institutional Animal Care and Use Committee. All in vivo experiments were conducted under pathogen-free conditions at the animal facility. BT474R cells were suspended in PBS $\left(2 \times 10^{6}\right.$ cells $\left./ 100 \mu \mathrm{l}\right)$ and subcutaneously implanted into the flank region of 6-7-week-old female nude mice weighing 18-22 g (Chengdu Medical College Animal Facility, Chengdu, China). The rats had ad libitum access to food and water, and were maintained under controlled lighting (12 h light/dark cycle) and temperature $\left(20-25^{\circ} \mathrm{C}\right)$. Once tumors had reached $50-60 \mathrm{~mm}^{3}$ volume, the mice were randomly assigned to three groups $(n=10)$, receiving either i) intraperitoneal (i.p.) injection of $100 \mu \mathrm{l}$ PBS (PBS only, twice a week); ii) i.p. injection of $\mathrm{C} 3 \mathrm{G}(6 \mathrm{mg} / \mathrm{kg}$ in $100 \mu \mathrm{l} \mathrm{PBS}$, twice a week); or iii) i.p. injection of $\mathrm{P} 3 \mathrm{G}(6 \mathrm{mg} / \mathrm{kg}$ in $100 \mu \mathrm{l} \mathrm{PBS}$, twice a week). Tumors were measured every 5 days. The mice were euthanized once the tumors reached $1,000 \mathrm{~mm}^{3}$ due to ethical requirements. All animals were euthanized by an overdose of $\mathrm{CO}_{2}$ at the end of the experiment. Tumor tissues were extracted for immunostaining and weighing.

Immunohistochemistry. Spleen, liver and kidney sections from formalin-fixed, paraffin-embedded tumor xenografts ( $4 \mu \mathrm{m})$ were subjected to immunohistochemical staining using anti-HER2 (cat. no. AB-5569), anti-Ki67 (cat. no. AB-2368) and anti-caspase 3 (cat. no. AB-2294) (all Rui Biological Ltd.) antibodies. Briefly, the tissue sections were deparaffinized and rehydrated, followed by treatment with citrate buffer ( $\mathrm{pH}$ 6.0) and 3\% hydrogen peroxide. The sections were then incubated with the primary antibodies for 30-60 min at room temperature, followed by an incubation with HRP-conjugated goat anti-rabbit IgG (cat. no. AB-0025; Rui Biological Ltd.) for $1 \mathrm{~h}$ at room temperature. Nuclei were counterstained with hematoxylin. The staining was visualized and recorded using a microscope (SZX16; Olympus Corporation).

Statistical analysis. In vitro data are presented as the mean \pm standard deviation $(n \geq 3)$. In vivo data are presented as the mean \pm standard error of the mean $(n=10)$. Data were analyzed by Student's t-test using SigmaPlot version 12.0 (Systat Software, Inc., San Jose, CA, USA). P $\leq 0.05$ was considered to indicate a statistically significant difference.

\section{Results}

Treatment with C3G or P3G sensitizes trastuzumab-resistant $M D A-M B-453 R$ and BT474R cell lines in vitro. To determine the ability of $\mathrm{C} 3 \mathrm{G}$ and $\mathrm{P} 3 \mathrm{G}$ to overcome trastuzumab resistance, two HER2-positive cell lines (MDA-MB-453 and BT474) and their trastuzumab-resistant cell lines (MDA-MB-453R and BT474R) were treated with 0.003 to $50 \mu \mathrm{M}$ (4-fold dilution) $\mathrm{C} 3 \mathrm{G}$ or $\mathrm{P} 3 \mathrm{G}$ for $48 \mathrm{~h}$. The calculated half maximal inhibitory concentration $\left(\mathrm{IC}_{50}\right)$ value for each cell line was determined (Fig. 1). Treatment with $\mathrm{C} 3 \mathrm{G}$ or P3G significantly inhibited cell growth in the parental and trastuzumab-resistant cells, as compared with the control cells (Fig. 1).

Treatment with C3G or P3G inhibits p-HER2, $p$-AKT and $p$-MAPK expression levels in vitro. The expression levels of p-HER2, and its downstream mediators AKT and MAPK, were assessed by western blotting. The expression levels of p-HER2, p-AKT (Ser473) and p-p44/42 MAPK were downregulated in MDA-MB-453, MDA-MB-453R, BT474 and BT474R cells following $24 \mathrm{~h}$ treatment with C3G $(5 \mu \mathrm{g} / \mathrm{ml})$ and P3G (5 $\mu \mathrm{g} / \mathrm{ml})$ (Fig. 2).

Treatment with C3G or P3G induces apoptosis in trastuzumab-resistant HER2-positive human breast cancer cells in vitro. The effects of $\mathrm{C} 3 \mathrm{G}$ or $\mathrm{P} 3 \mathrm{G}$ treatment on apoptosis were assessed by Annexin $\mathrm{V}$ and caspase 3/7 activity assays (Fig. 3). Following a 24 h treatment, MDA-MB-453 cells treated with trastuzumab, C3G or P3G exhibited $2.8 \pm 0.50,3.2 \pm 0.45$ and $4.0 \pm 0.34$ fold-changes in the number of Annexin V-positive cells, as compared with the control cells, respectively (Fig. 3A). In addition, following a $24 \mathrm{~h}$ treatment, MDA-MB-453R cells treated with trastuzumab, C3G or P3G exhibited $1.2 \pm 0.45,3.0 \pm 0.38$ and $3.5 \pm 0.44$ fold-changes in the number of Annexin V-positive cells, as compared with the control cells, respectively (Fig. 3A). Following a $24 \mathrm{~h}$ treatment, BT474 cells treated with trastuzumab, C3G or P3G exhibited $2.5 \pm 0.32,4.2 \pm 0.25$ and $5.5 \pm 0.40$ fold-changes in the number of Annexin V-positive cells, as compared with the control cells, respectively (Fig. 3B). Furthermore, following a $24 \mathrm{~h}$ treatment, BT474R cells treated with trastuzumab, C3G or P3G exhibited $1.5 \pm 0.55,3.8 \pm 0.23$ and $5.0 \pm 0.32$ fold-changes in the number of Annexin V-positive cells, as compared with the control cells, respectively (Fig. 3B).

Following a $48 \mathrm{~h}$ treatment, MDA-MB-453 cells treated with trastuzumab, $\mathrm{C} 3 \mathrm{G}$ or $\mathrm{P} 3 \mathrm{G}$ exhibited $3.1 \pm 0.40,12.0 \pm 2.10$ and $8.9 \pm 3.0$ fold-changes in caspase $3 / 7$ activity, as compared with the control cells, respectively (Fig. 3C). In addition, following a $48 \mathrm{~h}$ treatment, MDA-MB-453R cells treated with trastuzumab, $\mathrm{C} 3 \mathrm{G}$ or $\mathrm{P} 3 \mathrm{G}$ exhibited $1.2 \pm 0.31,10.2 \pm 1.80$ and $6.8 \pm 2.20$ fold-changes in caspase 3/7 activity, as compared with the control cells, respectively (Fig. 3C). Following a $48 \mathrm{~h}$ treatment, BT474 cells treated with trastuzumab, C3G or P3G exhibited $3.0 \pm 0.60,5.8 \pm 2.10$ and $9.2 \pm 1.80$ fold-changes in caspase $3 / 7$ activity, as compared with the control cells, respectively 


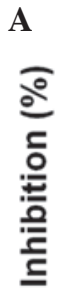

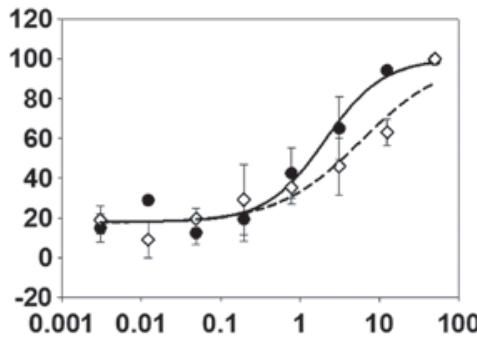

Drug concentration $(\mu \mathrm{M})$

- C3G (MDA-MB-453)

$I_{50}=1.40 \pm 0.92 \mu \mathrm{M}$

$\therefore \quad$ C3G (MDA-MB-453R)

---- $I C_{50}=3.82 \pm 1.08 \mu \mathrm{M}$

C

ํํㄹำ

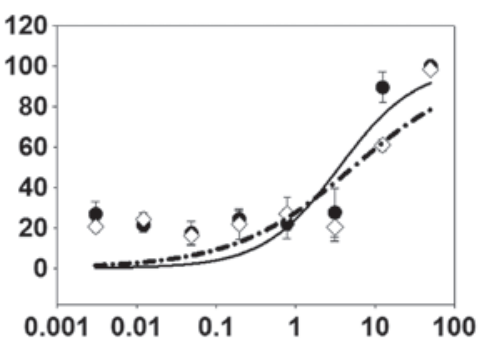

Drug concentration $(\mu \mathrm{M})$

- P3G (BT474)

$\mathrm{IC}_{50}=3.82 \pm 1.71 \mu \mathrm{M}$

$\diamond \quad$ P3G (BT474R)

.... IC $\mathrm{IC}_{50}=3.82 \pm 1.71 \mu \mathrm{M}$

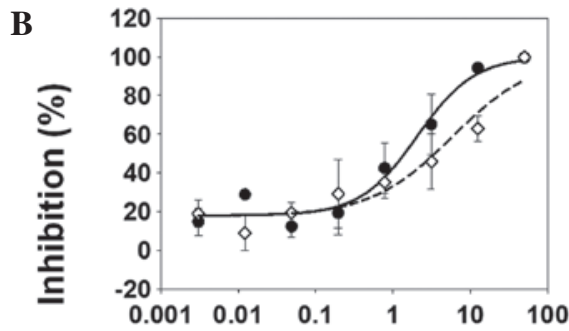

Drug concentration $(\mu \mathrm{M})$

- C3G (BT474)

$-\mathrm{IC}_{50}=1.40 \pm 0.92 \mu \mathrm{M}$

$\diamond \quad$ C3G (BT474R)

---- $\mathrm{IC}_{50}=3.82 \pm 1.08 \mu \mathrm{M}$

D

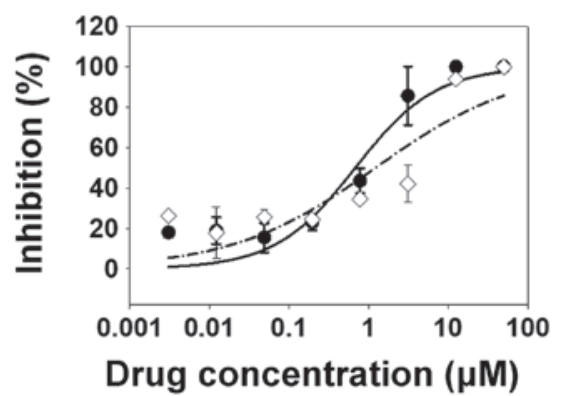

- P3G (MDA-MB-453)

$-\mathrm{IC}_{50}=1.07 \pm 0.23 \mu \mathrm{M}$

$\diamond \quad$ P3G (MDA-MB-453R)

.... IC $C_{50}=1.61 \pm 0.76 \mu \mathrm{M}$

Figure 1. Treatment with cyanidin-3-glucoside (C3G) or peonidin-3-glucoside (P3G) inhibits the growth of human epidermal growth factor receptor 2-positive cell lines. MDA-MB-453, MDA-MB-453 resistant (R), BT474 and BT474R cells were treated with C3G or P3G (concentration range 50 to $0.003 \mu \mathrm{M}, 4$-fold dilution) for 48 h. C3G inhibits (A) MDA-MB-453 and MDA-MB-453R and (B) BT474 and BT474R cell growth. P3G inhibits (C) BT474 and BT474R and (D) MDA-MB-453 and MDA-MB-453R cell growth. Data are presented as the mean \pm standard deviation.

\begin{tabular}{|c|c|c|c|c|}
\hline & $\begin{array}{c}\text { MDA-MB- } \\
453\end{array}$ & $\begin{array}{c}\text { MDA-MB- } \\
453 R\end{array}$ & BT474 & BT474R \\
\hline P3G & $-\quad+=$ & $=+-$ & $-+\cdot$ & $-+\cdot$ \\
\hline C3G & $-\quad-\quad+$ & $-\quad-\quad+$ & $-\quad-\quad+$ & $-\quad-\quad+$ \\
\hline p-HER2 & $5--$ & 5 & E- & $-\div-$ \\
\hline HER2 & --- & $-\infty$ & क- & $-\infty$ \\
\hline p-AKT (Ser473) & $-\cdots$ & - - & - & --- \\
\hline AKT & -- & $--\cdots$ & $--\cdots$ & $-\infty$ \\
\hline p-p44/42 MAPK & $-\equiv$ & से 둘 & 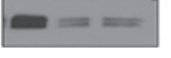 & - \\
\hline p44/42 MAPK & $==$ & $=2=$ & $-=$ & 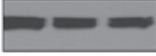 \\
\hline$\beta$-actin & $-\infty$ & $-\infty$ & $-\infty$ & --- \\
\hline
\end{tabular}

Figure 2. Effects of cyanidin-3-glucoside (C3G) or peonidin-3-glucoside (P3G) on human epidermal growth factor receptor 2 and downstream signaling pathways. MDA-MB-453, MDA-MB-453 resistant (R), BT474, and BT474R cells were treated with C3G (5 $\mu \mathrm{g} / \mathrm{ml})$ or P3G (5 $\mu \mathrm{g} / \mathrm{ml})$ for $24 \mathrm{~h}$ and whole-cell extracts were analyzed by western blotting with the indicated antibodies. MAPK, mitogen-activated protein kinases.

(Fig. 3D). Furthermore, following a $48 \mathrm{~h}$ treatment, BT474R cells treated with trastuzumab, C3G or P3G exhibited 1.1 \pm 0.23 ,
$4.4 \pm 1.20$ and $8.1 \pm 1.80$ fold-changes in caspase $3 / 7$ activity, as compared with the control cells, respectively (Fig. 3D). 

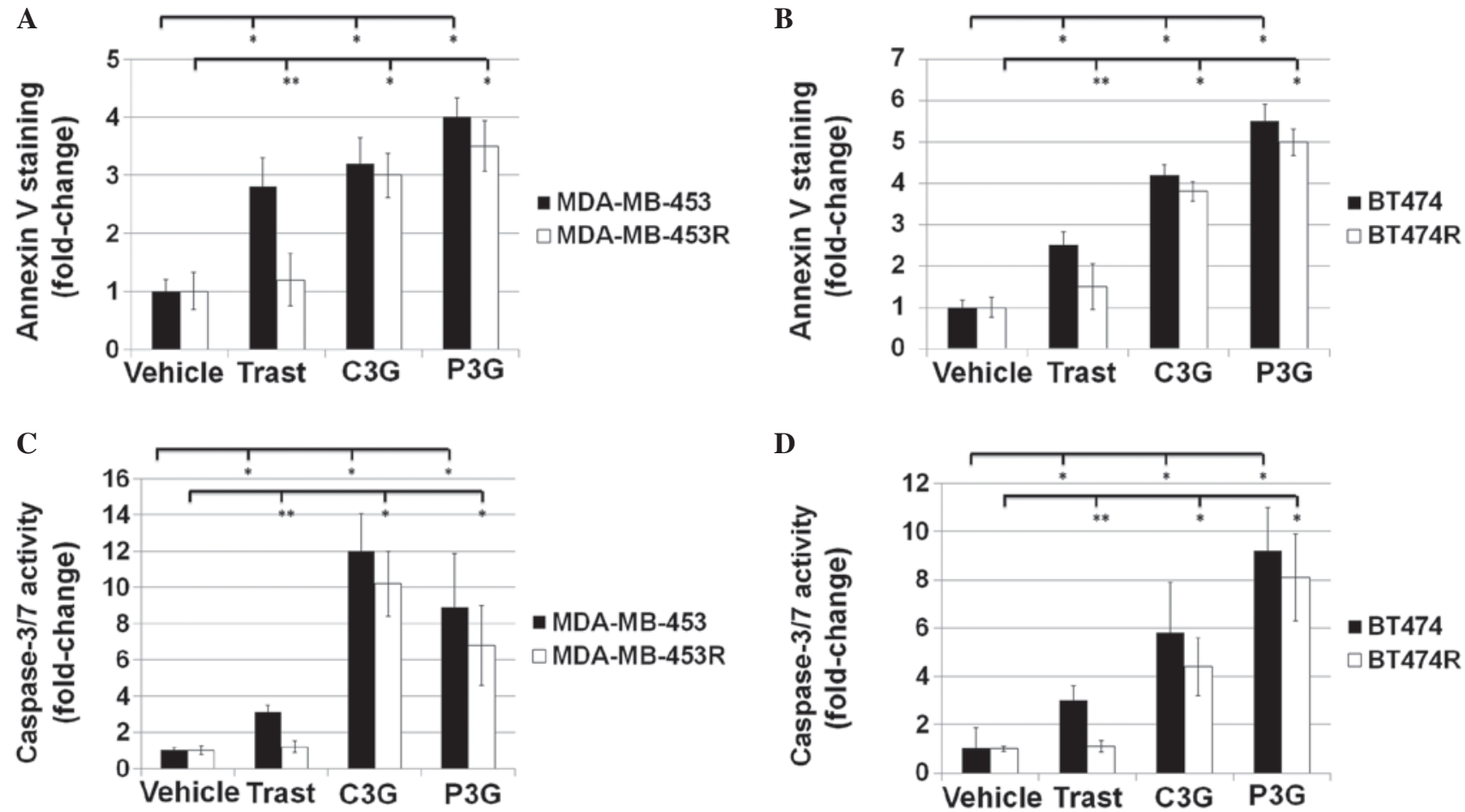

Figure 3. Treatment with cyanidin-3-glucoside (C3G) or peonidin-3-glucoside (P3G) induces cell apoptosis in human epidermal growth factor receptor 2 (HER2)-positive and trastuzumab (Trast)-resistant HER2-positive cell lines. (A and B) MDA-MB-453, MDA-MB-453 resistant (R), BT474 and BT474R cells were treated with dimethyl sulfoxide (DMSO, vehicle), Trast $(5 \mu \mathrm{g} / \mathrm{ml}), \mathrm{C} 3 \mathrm{G}(5 \mu \mathrm{g} / \mathrm{ml})$ or P3G $(5 \mu \mathrm{g} / \mathrm{ml})$ for $24 \mathrm{~h}$ and Annexin V-positive cells were counted using flow cytometry. Graphs exhibit fold-change in Annexin V positive cells. (C and D) MDA-MB-453, MDA-MB-453R, BT474 and BT474R cells were treated with DMSO (vehicle), Trast $(5 \mu \mathrm{g} / \mathrm{ml})$, C3G $(5 \mu \mathrm{g} / \mathrm{ml})$ or P3G $(5 \mu \mathrm{g} / \mathrm{ml})$ for $48 \mathrm{~h}$. Graphs exhibit fold-change in caspase $3 / 7$ activities. Data were normalized as caspase $3 / 7$ activity divided by cell viability. Data are presented as the mean \pm standard deviation; ${ }^{*} \mathrm{P}<0.05 ;{ }^{* *} \mathrm{P}>0.05$.

A

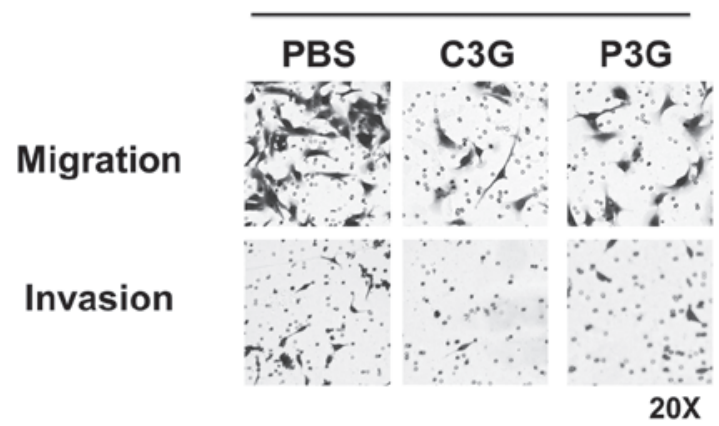

C

MDA-MB-435R

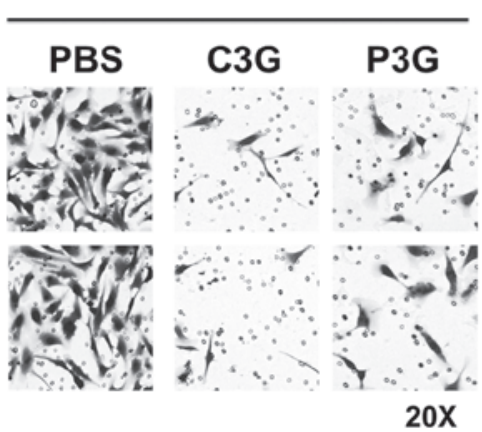

B

BT474R

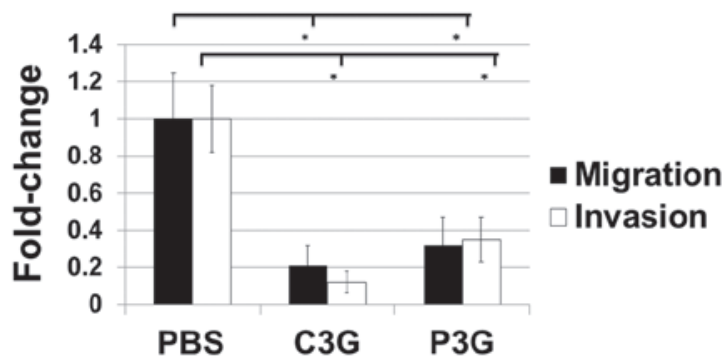

D

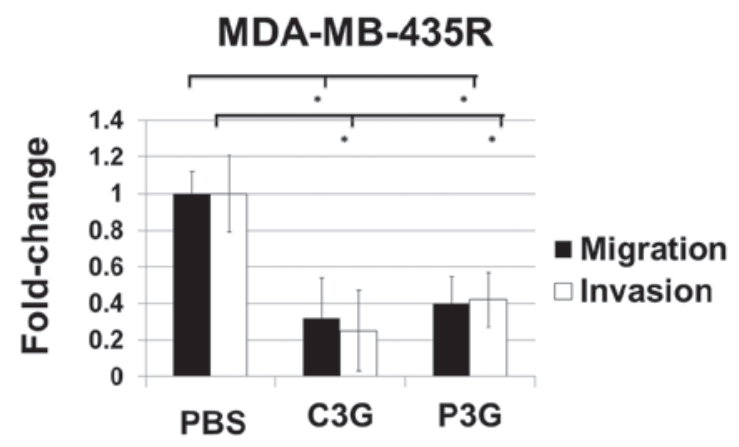

Figure 4. Effects of cyanidin-3-glucoside (C3G) and peonidin-3-glucoside (P3G) on the migration and invasion of human epidermal growth factor receptor 2-positive trastuzumab-resistant cells. (A and B) BT474 resistant (R) and (C and D) MDA-MB-435R cells were treated with vehicle, C3G $(1 \mathrm{mg} / \mathrm{ml})$ or P3G $(1 \mathrm{mg} / \mathrm{ml})$ for $48 \mathrm{~h}$. Representative images of migratory and invasive cells are shown. (B and D) Quantitative analysis of the number of migratory or invasive cells, as determined by counting cells under a microscope. Data are presented as the mean \pm standard deviation; ${ }^{*} \mathrm{P}<0.05$. 


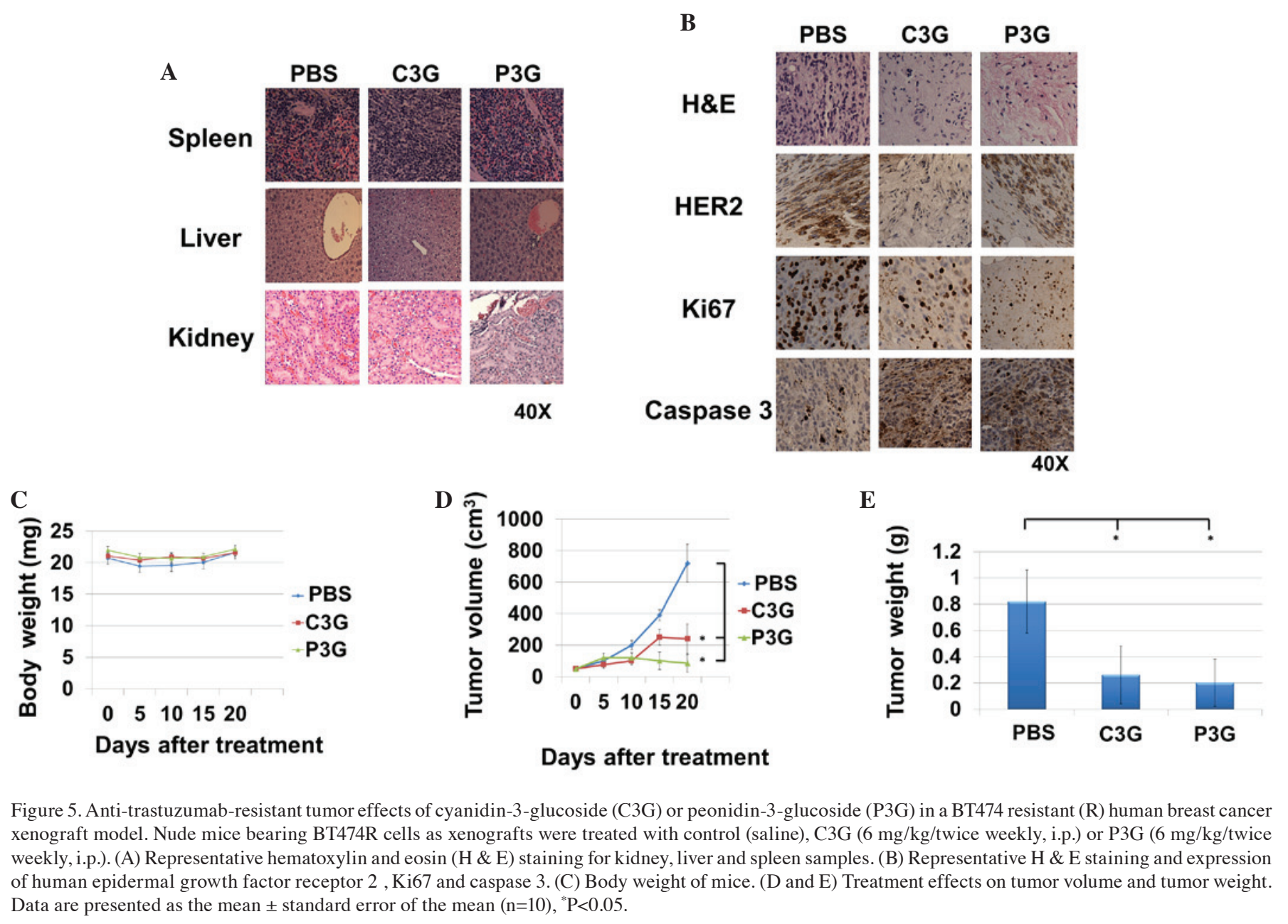

Treatment with C3G or P3G inhibits invasion and migration of trastuzumab-resistant human breast cancer cells in vitro. As determined by Transwell migration assay, the number of migrated BT474R cells treated with $\mathrm{C} 3 \mathrm{G}(0.21 \pm 0.11)$ or P3G $(0.32 \pm 0.15)$ were significantly lower, as compared with the vehicle-treated control cells $(1.0 \pm 0.25)$ (Fig. 4A upper panel and $\mathrm{B}$ ). In addition, the number of migrated MDA-MB-435R cells treated with C3G $(0.32 \pm 0.22)$ or P3G $(0.40 \pm 0.15)$ were significantly lower, as compared with the vehicle-treated control cells $(1.0 \pm 0.12)$ (Fig. 4C upper panel and D). As determined by Transwell invasion assays, the number of invasive BT474R cells treated with $\mathrm{C} 3 \mathrm{G}$ $(0.12 \pm 0.06)$ or P3G $(0.35 \pm 0.12)$ were significantly lower, as compared with the vehicle-treated control cells $(1.0 \pm 0.18)$ (Fig. 4A lower panel and B). Furthermore, the number of invasive MDA-MB-453R cells treated with C3G $(0.25 \pm 0.22)$ or P3G $(0.42 \pm 0.15)$ were significantly lower, as compared with the vehicle-treated control cells $(1.0 \pm 0.21)$ (Fig. $4 \mathrm{C}$ lower panel and D).

Treatment with $C 3 G$ or $P 3 G$ reduces trastuzumab-resistant cell-mediated tumor growth in vivo. The in vivo anti-trastuzumab-resistant tumor growth activities of $\mathrm{C} 3 \mathrm{G}$ or P3G were determined using BT474R cells. A pilot study was conducted to determine drug tolerance at the indicated levels, and no signs of organ damage were observed (8). After the experiment, the harvested kidney, liver and spleen samples from each treatment group were indistinguishable from the control group (Fig. 5A). Histopathological studies demonstrated that tumors treated with $\mathrm{C} 3 \mathrm{G}$ or $\mathrm{P} 3 \mathrm{G}$ expressed lower levels of HER2, as well as the proliferation maker Ki67, as compared with the control group (Fig. 5B). In addition, tumors treated with C3G or P3G expressed higher levels of caspase 3, as compared with the control group (Fig. 5B). During the experiment, body weight of the mice in the $\mathrm{C} 3 \mathrm{G}$ or $\mathrm{P} 3 \mathrm{G}$ treatment groups was indistinguishable from those in control groups (Fig. 5C). Mice treated with $\mathrm{C} 3 \mathrm{G}$ or $\mathrm{P} 3 \mathrm{G}$ exhibited a $\sim 67$ or $\sim 88 \%$ reduction in tumor volume at day 20 , respectively (Fig. 5D), and a $\sim 68$ or $\sim 76 \%$ reduction in tumor weight at day 20, respectively (Fig. 5E).

\section{Discussion}

It has previously been reported that $\mathrm{C} 3 \mathrm{G}$ and $\mathrm{P} 3 \mathrm{G}$ inhibit $\mathrm{G}_{2} / \mathrm{M}$ arrest, downregulate cyclin-dependent kinase expression, and induce caspase- 3 activation, chromatin condensation and cell death in vitro (11). In addition, mulberry anthocyanins, cyanidin 3-rutinoside and $\mathrm{C} 3 \mathrm{G}$, have been reported to inhibit the migration and invasion of human lung cancer cells (12). Numerous in vivo experiments have also suggested promising anti-tumor activities of anthocyanins. C3G has been shown to inhibit human lung tumor growth in xenograft models, including carcinoma cell A549 and Lewis lung carcinoma cell tumor-bearing models $(11,13)$. In addition, bilberry-derived C3G was able to inhibit intestinal adenoma formation in an 
Apc (Min) mouse model (14). Previous preclinical studies have also detected the antitumor efficacy of C3G and P3G (7,11-19).

In our previous study, we confirmed that the pharmacological activity of $\mathrm{C} 3 \mathrm{G}$ and $\mathrm{P} 3 \mathrm{G}$ alone in HER2-positive cell lines was dependent on the inhibition of HER2 activity (7). In addition, a series of experiments were conducted, which were designed to examine the synergism between $\mathrm{C} 3 \mathrm{G}$ and trastuzumab, which demonstrated that anthocyanins were able to significantly enhance trastuzumab-induced growth inhibition in representative HER2-positive cell lines, including MDA-MB-453, BT474 and HCC156 cells in vitro. In addition, treatment with $\mathrm{C} 3 \mathrm{G}$ in combination with trastuzumab resulted in a more potent inhibition of tumor growth in a BT474 tumor-bearing mouse model, as compared with the control, C3G or trastuzumab treatment groups. These data supported the need for further studies to explore the therapeutic potential of anthocyanin components in combination with trastuzumab in HER2-positive breast cancer.

The in vitro and in vivo data reported in the present study indicated that $\mathrm{C} 3 \mathrm{G}$ or $\mathrm{P} 3 \mathrm{G}$ treatment may inhibit the activity of HER2, AKT and MAPK in HER2-positive MDA-MB-453 and BT474 cells, as well as in trastuzumab-resistant MDA-MB-453R and BT474R cells. Treatment with $\mathrm{C} 3 \mathrm{G}$ or $\mathrm{P} 3 \mathrm{G}$ induced apoptosis in the trastuzumab-resistant cells and suppressed the migration and invasion of these cells. In conclusion, C3G and P3G were able to significantly inhibit the growth of trastuzumab-resistant cells in vitro and in vivo. These results support the requirement for further studies that explore the therapeutic potential of anthocyanins in the treatment of patients with trastuzumab-resistant breast cancer. Further studies with regards to overcoming drug resistance are also essential.

\section{Acknowledgements}

The authors of the present study would like to thank the Chengdu Medical College flow-cytometry core facility and the animal core facility for their help conducting in vitro and in vivo studies. The present study was supported by the Sichuan Province Health Bureau (grant no. 110465) and the National Natural Science Foundation of China (grant no. 81273074).

\section{References}

1. American Cancer Society: Cancer Facts \& Figures 2015 American Cancer Society, Atlanta, GA, 2015.

2. Lv F, Yu Y, Zhang B, Liang D, Li ZM and You W: Inhibitory effects of mild hyperthermia plus docetaxel therapy on ER(+/-) breast cancer cells and action mechanisms. J Huazhong Univ Sci Technolog Med Sci 33: 870-876, 2013.
3. Bedard PL, Cardoso F and Piccart-Gebhart MJ: Stemming resistance to HER-2 targeted therapy. J Mammary Gland Biol Neoplasia 14: 55-66, 2009.

4. Slamon DJ, Clark GM, Wong SG, Levin WJ, Ullrich A and McGuire WL: Human breast cancer: Correlation of relapse and survival with amplification of the HER-2/neu oncogene. Science 235: 177-182, 1987.

5. Hynes NE and Lane HA: ERBB receptors and cancer: The complexity of targeted inhibitors. Nat Rev Cancer 5: 341-354, 2005.

6. Vrbic S, Pejcic I, Filipovic S, Kocic B and Vrbic M: Current and future anti-HER2 therapy in breast cancer. J BUON 18: 4-16, 2013.

7. Liu W, Xu J, Wu S, Liu Y, Yu X, Chen J, Tang X, Wang Z, Zhu X and $\mathrm{Li} \mathrm{X}$ : Selective anti-proliferation of HER2-positive breast cancer cells by anthocyanins identified by high-throughput screening. PLoS One 8: e81586, 2013.

8. Liu W, Xu J, Liu Y, Yu X, Tang X, Wang Z and Li X: Anthocyanins potentiate the activity of trastuzumab in human epidermal growth factor receptor 2-positive breast cancer cells in vitro and in vivo. Mol Med Rep 10: 1921-1926, 2014.

9. Nahta R, Takahashi T, Ueno NT, Hung MC and Esteva FJ: P27(kip1) down-regulation is associated with trastuzumab resistance in breast cancer cells. Cancer Res 64: 3981-3986, 2004.

10. Nahta R and Esteva FJ: In vitro effects of trastuzumab and vinorelbine in trastuzumab-resistant breast cancer cells. Cancer Chemother Pharmacol 53: 186-190, 2004.

11. Chen PN, Chu SC, Chiou HL, Chiang CL, Yang SF and Hsieh YS: Cyanidin 3-glucoside and peonidin 3-glucoside inhibit tumor cell growth and induce apoptosis in vitro and suppress tumor growth in vivo. Nutr Cancer 53: 232-243, 2005.

12. Chen PN, Chu SC, Chiou HL, Kuo WH, Chiang CL and Hsieh YS: Mulberry anthocyanins, cyanidin 3-rutinoside and cyanidin 3-glucoside, exhibited an inhibitory effect on the migration and invasion of a human lung cancer cell line. Cancer Lett 235: 248-259, 2006.

13. Ding M, Feng R, Wang SY, Bowman L, Lu Y, Qian Y, Castranova V, Jiang $\mathrm{BH}$ and Shi X: Cyanidin-3-glucoside, a natural product derived from blackberry, exhibits chemopreventive and chemotherapeutic activity. J Biol Chem 281: 17359-17368, 2006.

14. Cooke D, Schwarz M, Boocock D, Winterhalter P, Steward WP, Gescher AJ and Marczylo TH: Effect of cyanidin-3-glucoside and an anthocyanin mixture from bilberry on adenoma development in the ApcMin mouse model of intestinal carcinogenesis - relationship with tissue anthocyanin levels. Int J Cancer 119: 2213-2220, 2006.

15. Fernandes I, Marques F, de Freitas V and Mateus N: Antioxidant and antiproliferative properties of methylated metabolites of anthocyanins. Food Chem 141: 2923-2933, 2013.

16. Kamenickova A, Anzenbacherova E, Pavek P, Soshilov AA, Denison MS, Zapletalova M, Anzenbacher P and Dvorak Z: Effects of anthocyanins on the AhR-CYP1A1 signaling pathway in human hepatocytes and human cancer cell lines. Toxicol Lett 221: 1-8, 2013

17. Chen XQ, Nagao N, Itani T and Irifune K: Anti-oxidative analysis and identification, and quantification of anthocyanin pigments in different coloured rice. Food Chem 135: 2783-2788, 2012.

18. Fernandes I, Faria A, Azevedo J, Soares S, Calhau C, De Freitas V and Mateus N: Influence of anthocyanins, derivative pigments and other catechol and pyrogallol-type phenolics on breast cancer cell proliferation. J Agric Food Chem 58: 3785-3792, 2010.

19. Heinonen M: Antioxidant activity and antimicrobial effect of berry phenolics - a Finnish perspective. Mol Nutr Food Res 51: 684-691, 2007. 